\title{
PAISAGISMO E MODERNIDADE NA EUROPA NA DÉCADA DE 1920
}

\author{
LANDSCAPE AND MODERNITY IN EUROPE IN THE 1920'S
}

\begin{abstract}
SANDEVILLE JR., Euler
Professor Doutor da Faculdade de Arquitetura e Urbanismo da USP. Coordenador da Área de Concentração Paisagem e Ambiente do Programa de Pós-Graduação em Arquitetura e Urbanismo da USP e do Laboratório Gestão e Projeto do Espaço. Professor orientador dos Programas de Pós-Graduação em Arquitetura e Urbanismo e em Ciência Ambiental da USP. Editor das revistas eletrônicas Paisagens em Debate e Linguagens. Sites: http://www.ambiente.arq.br e http://www. linguagens.art.br.
\end{abstract}

\section{DERNTL, Maria Fernanda}

Arquiteta e Urbanista, mestre em Estruturas Ambientais Urbanas (FAU.USP), Doutoranda em Arquitetura e Urbanismo (FAU.USP).

\section{RESUMO}

Experiências formais realizadas a partir do final da Primeira Guerra deram novo impulso à reformulação das concepções então correntes para os jardins. Notamos algumas tendências contrastantes que coexistiam nessa época: uma, então dominante, representada por um ambiente profissional respondendo a uma demanda particular e do Estado, de caráter conservador e nacionalista, outras, de renovação, representadas por paisagistas e por arquitetos de alguma forma vinculados às vanguardas.

O objetivo deste trabalho é destacar duas tendências modernizantes atuando na produção paisagística na Europa dos anos de 1920. Uma delas, desenvolvida por paisagistas e arquitetos, mostra forte influência do cubismo e do expressionismo, convergindo para o art déco, dotada de forte conotação decorativa. Gabriel Guevrekian e Robert Mallet-Stevens, são alguns dos representantes dessa tendência.

Outra tendência modernizante deve-se à atuação de representantes do nascente movimento moderno em arquitetura, tanto em sua abordagem dos jardins como também nos conceitos que empregaram na criação de espaços externos. Entre a ampla gama de experiências nesse sentido, vêem-se as posturas bem diversas apresentadas por arquitetos como Le Corbusier e Erik Gunnar Asplund.

Palavras-chave: Paisagismo, jardins, modernidade, vanguardas, arquitetura.

\begin{abstract}
Formal experiences made since the end of the First World War gave new impetus to the reformulation of conceptions currently applied to garden design We took notice of contrasting trends coexisting at that time: on one side, an overruling tendency developed by a group of professionals that fulfilled the demands both from private clients and from the estate, which presented a traditional and nationalist character; on another side were the renewal trends developed by landscape architects and architects linked somehow to the artistic avant-garde.

The purpose of this article is to point out two modernizing trends affecting landscape design production during the 1920's in Europe. One of these trends, developed by landscape designers and architects, is strongly influenced by Cubism and Expressionism, associated to art déco, thus bearing a highly ornamental connotation. Gabriel Guevrekian and Robert Mallet-Stevens are among the supporters of this trend. Another modernizing trend originates from the work of the members of early modern movement, as much in their approach to garden design as in the concepts employed by them to create exterior space. Among a wide range of experiences in this field it is possible to notice distinct positions assumed by architects such as Le Corbusier and Erik Gunnar Asplund.
\end{abstract}

Key words: Landscape design, gardens, modernity, avant-garde, architecture. 


\section{Historiografia do jardim moderno europeu}

A despeito da relevância das tendências de renovação nos jardins na década de 20 e 30, a bibliografia corrente não analisa a produção paisagística desse período de modo mais detido. Assim, os jardins europeus desse período permaneceram relegados a um plano secundário, constituindo uma séria lacuna na história cultural e da arte no período .

Pode-se tomar um manual de ampla difusão, como o de Geoffrey e Susan Jellicoe (JELLICOE 1987), para se ter uma idéia do modo como o paisagismo ${ }^{b}$ europeu na primeira metade do século XX é abordado. Observa-se aí, por um lado, uma dispersão de tendências importantes; por outro lado, também parece haver uma certa dificuldade em reconhecer as relações entre as vanguardas artísticas e arquitetônicas com o paisagismo. Para a Europa, os autores enfatizam o nascimento da "modern science of town - and country - planning" e da arquitetura moderna como propícios à renovação dos jardins. São apresentados trabalhos de Gertrude Jeckyll, Antonio Gaudí, Gunnar Asplund, Christopher Tunnard (com Chermayeff, em Sussex), C. Th. Sorensen (Aarhus University) e Holger Blom (Diretor de Parques de Estocolmo). Os autores, entretanto, deixam de apresentar uma série de experiências que estabeleciam vínculos importantes com as vanguardas artísticas e arquitetônicas da década de 20, como, por exemplo, aquelas realizadas por Guevrekian.

Michael Laurie (LAURIE 1978), no capítulo The Garden in History de seu clássico livro Landscape Architecture, inicia sua análise pela Babilônia e, na sua revisão do paisagismo europeu, chega apenas até o paisagismo pitoresco inglês do século XVIII, trabalhando a seguir os EUAc. Esta abordagem parece privilegiar aquilo que o autor consideraria mais relevante para o entendimento das referências do paisagismo estadunidense contemporâneo, desconsiderando toda experiência européia nos séculos XIX e XX.

Possíveis explicações para essa lacuna podem ser encontradas nos pressupostos em que se assenta a historiografia sobre esse período, de feição teleológica e engajada com as vanguardas, em geral corroborando pelo desinteresse por outras representações em sua historicidade. A decorrente valorização de uma racionalidade técnica particular, de uma estética construtivista e purista, e do domínio sobre a natureza, parece ter levado alguns autores a presumir que haveria também uma oposição entre a "máquina de morar" modernista e a presença da natureza encontrada no jardim. Além disso, como lembra Brown (BROWN 2000:8), jardins são vinculados a particularidades do ambiente local - como o solo e o clima - o que poderia ser considerado incompatível com os padrões internacionais associados à arquitetura moderna. Entretanto, essa hipótese deve ser relativizada e contextualizada.

Uma outra possível explicação para o insuficiente reconhecimento dos desenvolvimentos no campo dos jardins no período das vanguardas artísticas pode estar relacionada à ascensão dos regimes totalitários. De fato, em decorrência das guerras e regimes totalitários ${ }^{d}$, a migração para os EUA de intelectuais e artistas como Neutra, Gropius e Tunnard, já na primeira metade do século $X X$, foi de imensa influência no paisagismo daquele país. Esses profissionais foram acolhidos por uma política oficial de renovação nos EUA, que lhes abria espaço nas universidades e instituições artísticas. De qualquer modo, deve-se observar que a lacuna em relação aos estudos sobre os jardins das primeiras décadas do século XX não se restringe à Europa, mas também compreende os EUAe.

O interesse pelo jardim europeu da primeira metade do século XX renovou-se a partir da década de 90 e desde então essa lacuna na historiografia começa a ser preenchida. Isso ocorre em um contexto em que a crítica à historiografia modernista está avançada para outras áreas e em que o paisagismo reassume um papel importante na requalificação das cidades européias, a partir da constituição do Mercado Comum e da retomada de sua função de centro irradiador da cultura no novo contexto da globalização. Abriu-se assim a perspectiva de uma revisão recente dos 
consensos sobre os primeiros momentos do paisagismo moderno, para o que contribuiu também a estruturação de núcleos internacionais de pesquisa e o interesse na preservação dos jardins históricos modernistas, inseridos na pauta dos organismos de preservação dessa culturaf.

Uma bibliografia específica sobre a história do paisagismo (BROWN 2000, TREIB 1993, TREIB 2002, WAYMARK 2003, IMBERT 1993, LE DANTEC 2002) vem contribuindo para ampliar o conhecimento das idéias e intenções dos projetos de jardins desde o fim do século XIX até a contemporaneidade, em abordagens que se referenciam em discussões mais gerais a respeito da cultura artística, arquitetônica e ambiental ${ }^{9}$. Em relação ao período posterior à Segunda Guerra Mundial não há uma mudança mais significativa no quadro de entendimento, mas há um notável avanço de estudos (por exemplo, TREIB 2002), que começam a incluir experiências contrárias ao modernismo nesse período, como a alemã.

\section{À procura de uma modernidade}

A tentativa de aproximação às novas correntes plásticas que se desenvolviam desde o início do século XX parece ter contribuído para a aplicação de motivos geométricos em jardins que trazem referências do art déco, do cubismo e do expressionismo. Embora não logrem nesse momento a constituição efetiva de uma linguagem moderna do paisagismo ${ }^{\text {h }}$, seguramente se aproximam das vanguardas' como um esforço de fundar uma nova visibilidade para os jardins. Na exposição de Paris de 1925, o Jardin de l'habitation moderne, ou "jardim com árvores de concreto" de Robert Mallet-Stevensi pode ser considerado um marco na divulgação para o público de um novo gosto para jardins. Uma outra obra apresentada nessa Exposição, o Jardin d'eau et lumière, de Gabriel Guevrekian, fez uso de materiais até então alheios ao mundo dos jardins, como vidro, concreto e luz elétrica.

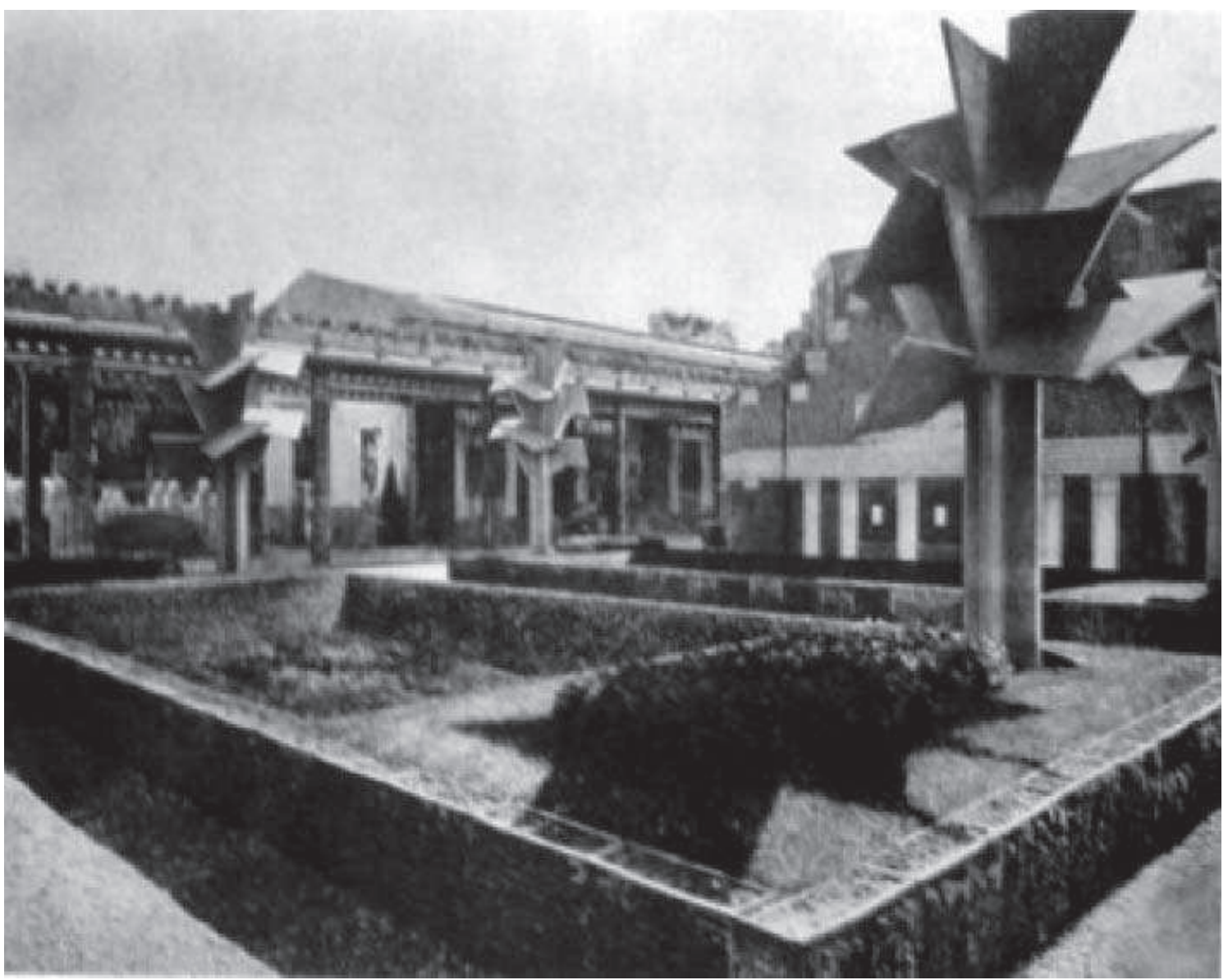

Figura 1: Jardin de I'habitation moderne, Robert Mallet-Stevens, 1925 (WAYMARK, 2003, p. 80) 


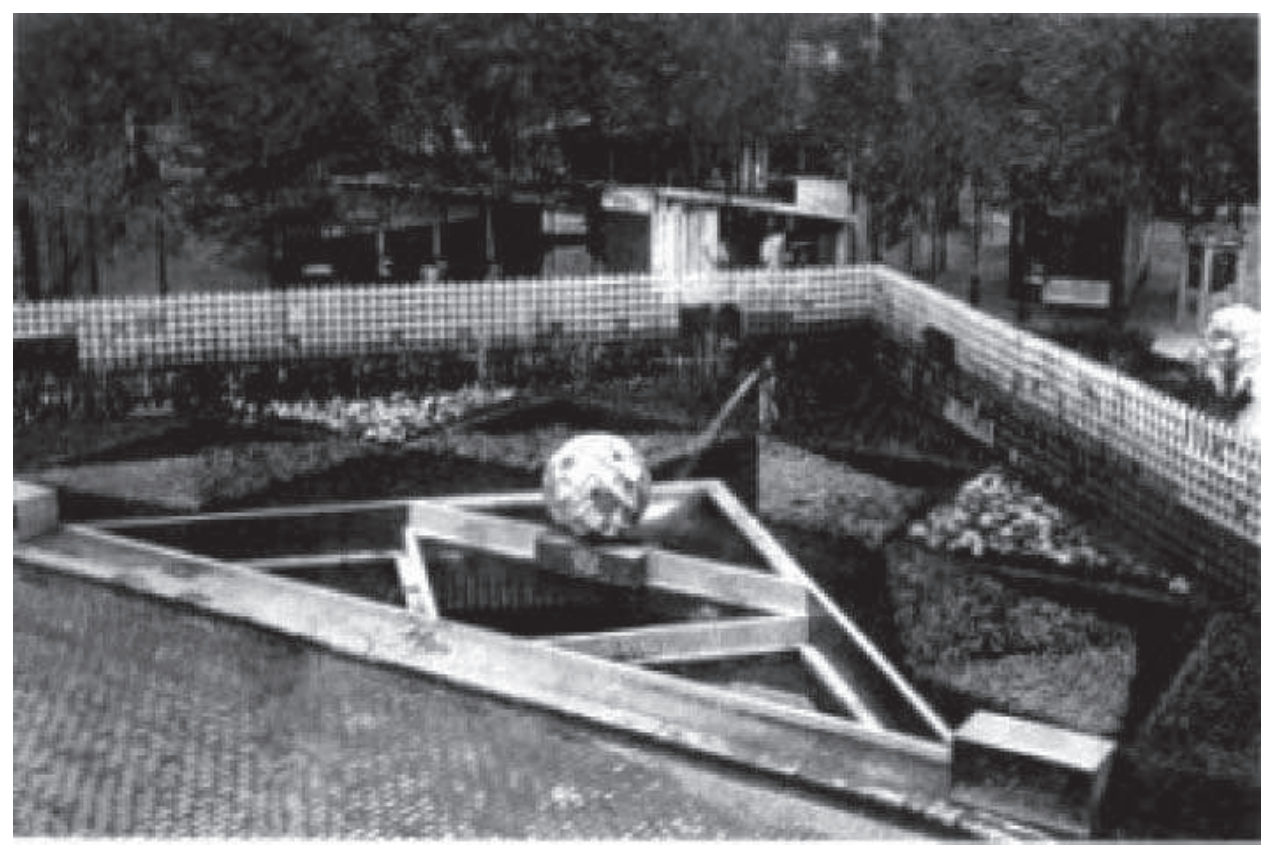

Figura 2: Jardin d'eau et lumière, de Gabriel Guevrekian (WAYMARK, 2003, p. 81)

O jardim da Villa Noailles, em Hyères, na França, de 1927, também projetado por Gabriel Guevrekian é uma das obras do período entre-guerras que vem sendo reabilitada mais recentemente. Trata-se de um jardim de planta triangular nos fundos de uma casa projetada por Mallet-Stevens. A composição do jardim baseia-se em motivos geométricos aplicados a canteiros para plantas, alternados por setores retangulares de piso revestido por pastilhas de vidro, além de um espelho d'água, triângulos escalonados e arbustos de forma esférica. Ao que parece, não fora o aspecto nitidamente decorativo da exposição e dos jardins mencionados, esses trabalhos haveriam sido reconhecidos pela historiografia como experimentações de vanguarda.

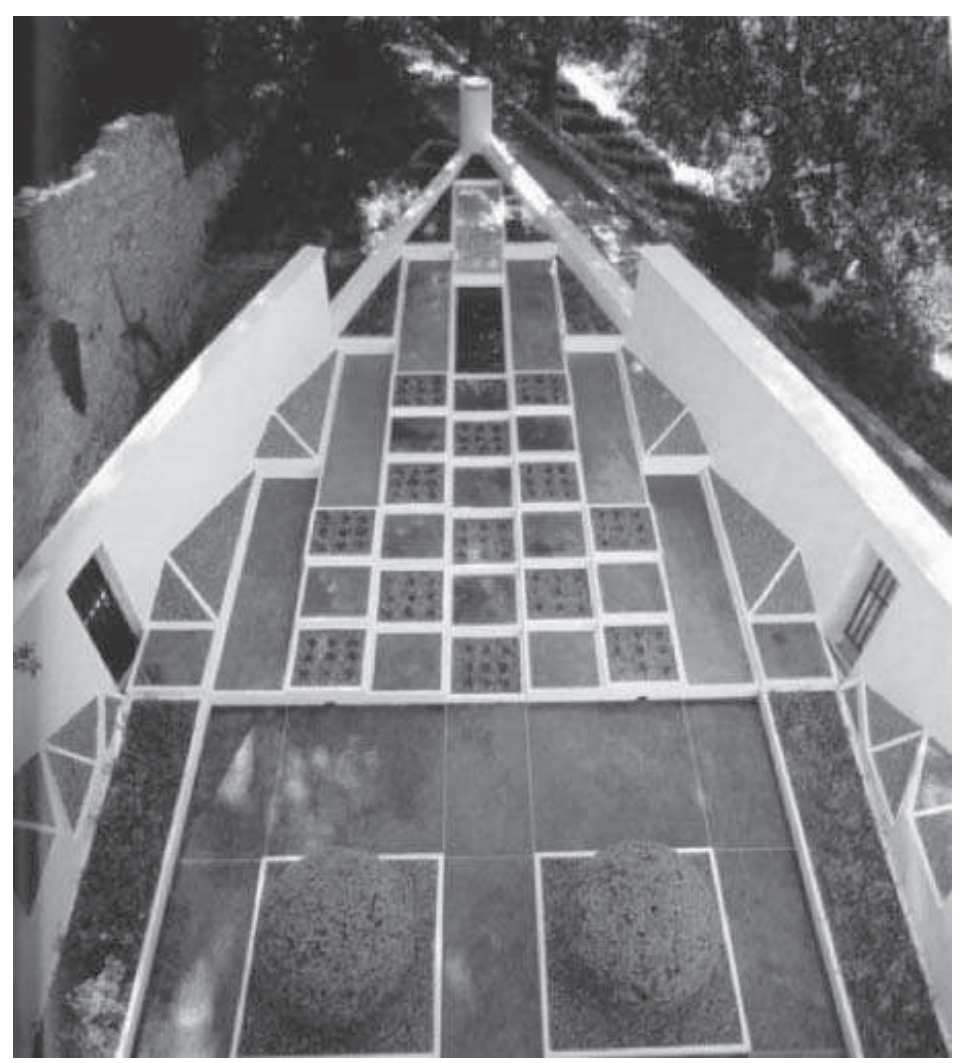

Figura 3: Villa Noailles-Hyeres, 1927, edifício: Mallet-Stevens, jardins: Guevrekian 
Outra tendência da modernidade nos jardins nas décadas de 20 e 30 está relacionada aos arquitetos envolvidos na pesquisa de uma nova síntese na relação do edifício com seu exterior. Neste sentido, pode-se lembrar de arquitetos como Frank Lloyd Wright, ainda no início do século e de Gerrit Rietveld, após a I Guerra, demonstrando as possibilidades de articulação de planos de fechamento e de planos transparentes, bem como de arquitetos da Bauhaus trabalhando uma liberação de volumes e de Le Corbusier liberando planos de piso e de cobertura.

Pesquisas recentes, retomando trabalhos pioneiros do movimento De Stijl e da Bauhaus, vêm mostrando que o projeto de jardins podia estar integrado às outras artes e também foi objeto de experimentações conduzidas por aqueles grupos. Um exemplo disso é uma escultura de jardim, de 1919, de Theo Van Doesburg, composta por grupos de flores dispostos em prismas geométricos de diferentes tamanhos, onde é possível ver a estreita relação com as composições de Piet Modriank. Mais significativo do que essa escultura de jardim é um projeto de Van Doesburg de 1921 para um jardim em que jogos de superfícies coloridas e formas geométricas ortogonais são aplicadas ao plano de piso. A estética do neoplasticismo teve efetiva influência em alguma experimentação alemã de jardins na década de 1920', em trabalhos de Hans Friedrich Pohlenz, Heinz Wichmann (vinculado à Bauhaus) e Georg Bela Pniower ${ }^{m}$.

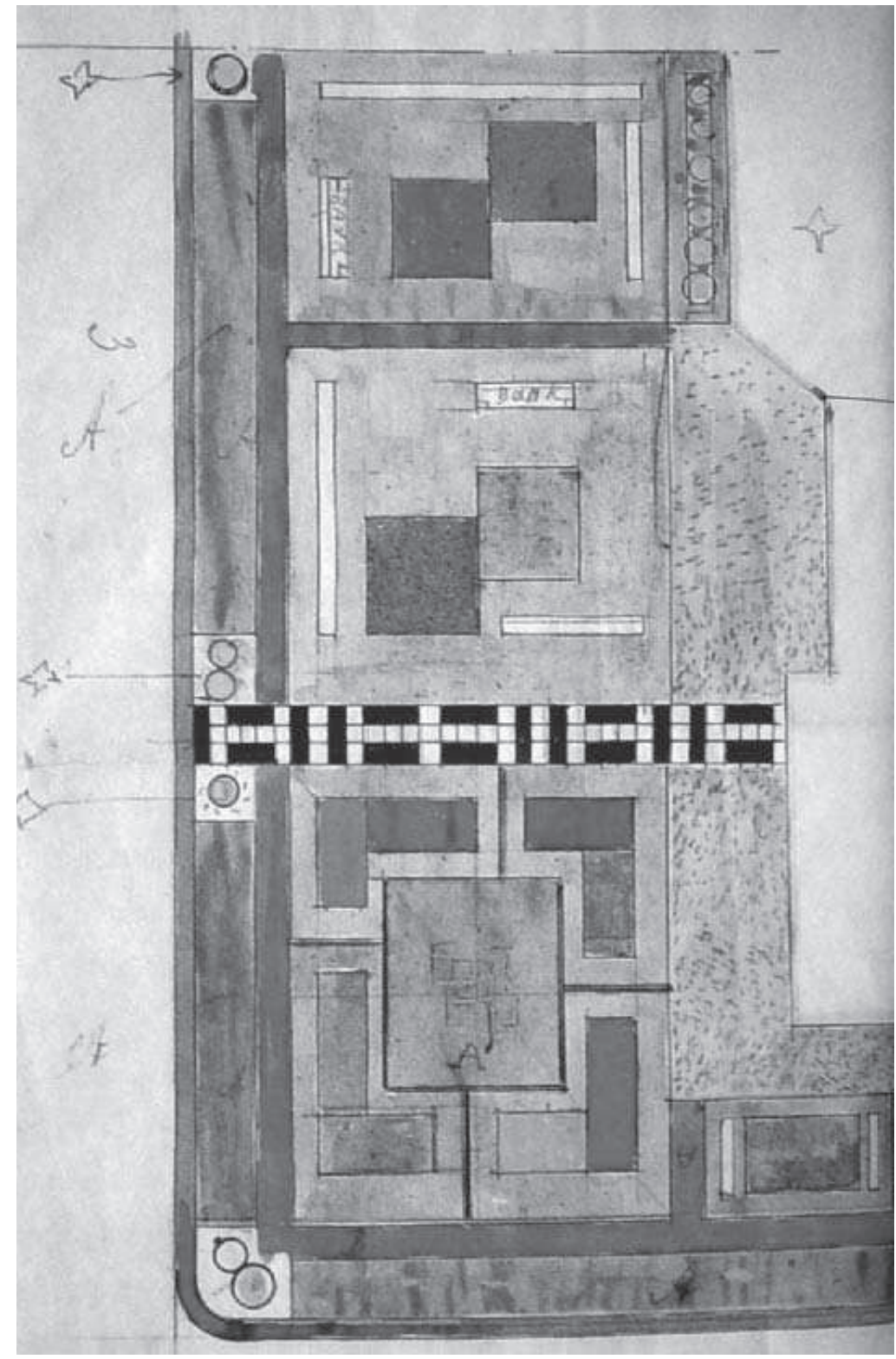

Figura 4: Detalhe de projeto de jardim, Van Doesburg, 1921 (LE DANTEC, 2002, p. 164) 


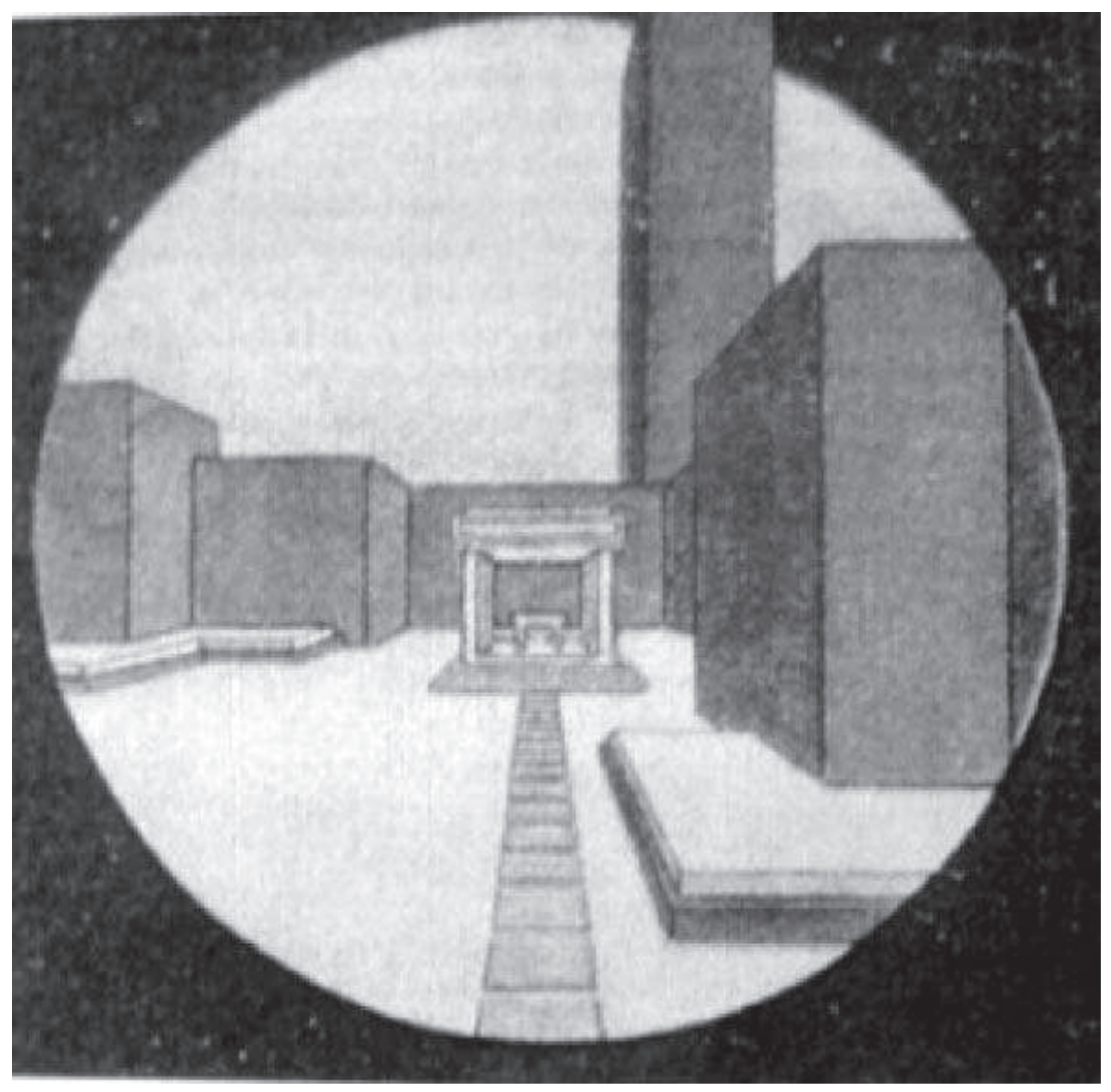

Figura 5: Geometria como expressão de modernidade: Pohlenz, $\bigcirc$ jardim singular, publicado em 1926 (WOLSCHKE-BULMAHN, 2005, p. 47)

Um entendimento da produção paisagística das primeiras décadas do século XX não pode deixar de considerar a atuação de Le Corbusier. A relação entre arquitetura e espaço externo na obra de Le Corbusier é freqüentemente entendida partir da análise da Villa Savoye, em Poissy de 1929. Assim, destaca-se a oposição entre seu volume branco e regular, independente da paisagem ao seu redor. No entanto, como se pode ver em perspectivas de cidades e de edifícios, suas obras também podiam prever uma rica vegetação arbórea em meio às construções, naquilo que parece ser uma incorporação e reinterpretação do ideário da cidade jardim (devemos lembrar, também nesse sentido, do pioneirismo de Tony Garnier com sua Cité Industrielle e a importância que dá à vegetação em seus projetos, como no Parc de la Tête-d'Or de 1904, na Villa Madame Garnier, Saint-Ramber 1912-1919 ou no projeto para o Concours Pour Le Parc boisé de Parilly, de 1936). O projeto de Le Corbusier para "Une Ville Contemporaine" (de 3 milhões de habitantes) exposta no Salon d'Automne de 1922, por exemplo, insere as quadras residenciais em densa arborização e implanta a oeste, em contraste com o reticulado do tecido urbano, um grande parque de desenho pitoresco e de fácil acesso ao centro comercial.

Deixando de lado a improvável idéia de que a vegetação estivesse presente nos croquis de Le Corbusier apenas como ambientação ilustrativa, podemos vê-los como expressão de um ideário determinado. Seus espaços verdes parecem ter um tratamento formal que vai além do mero atendimento de uma dimensão funcional ligada a exigências de lazer e salubridade.

Na obra de Corbusier ainda de meados dos anos 20 há casos de jardins que apresentam uma nítida herança de elementos tradicionais. Por exemplo, no Jardim da Villa Berque, em Auteuil, ca. 1926, estão presentes princípios derivados do estilo Sezession de Viena (BENTON 1987:106). Embora a obra de Le Corbusier já tenha sido bastante estudada, permanecem pouco esclarecidos casos como os jardins dotados de caramanchão da casa Ternisien em Boulogne-sur-Seine, 
de 1925 ou os prolongados trabalhos de preparação do terreno da Villa Stein de Monzie, em Garches, pelo jardineiro Crépin, em 1926 e, mais tarde, em 1927 e 1928, um extenso trabalho de paisagismo envolvendo arbustos variados e árvores frutíferas de diferentes tipos no terreno da mesma casa. Vale lembrar ainda que entre os arquitetos que participaram do desenho do Weissenhof (1929), Le Corbusier foi o único que desenhou seu próprio jardim (segundo WOLSCHKE-BULMAHN 2005:54).

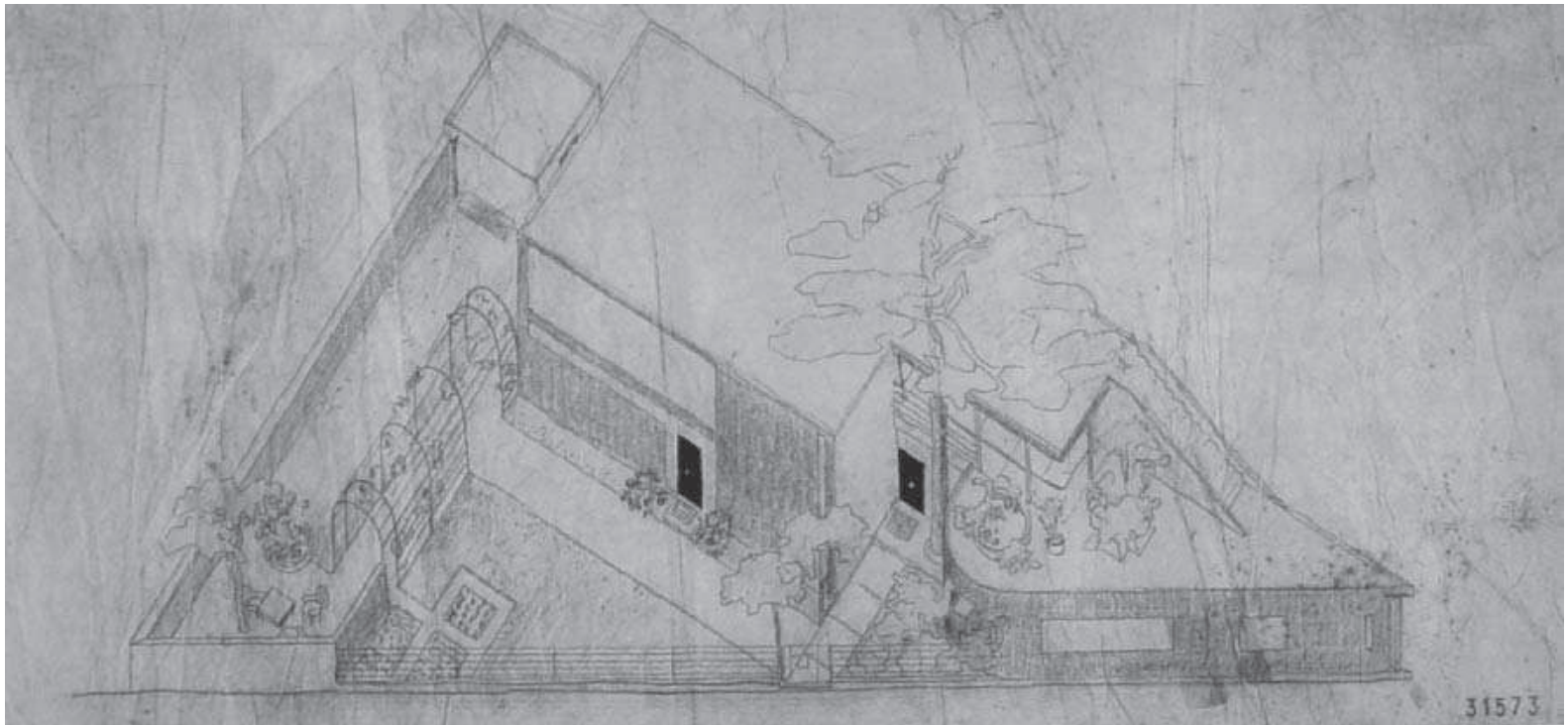

Figura 6: Le Corbusier, proposta da casa e jardim da Sra. Termisien, 1925 (BROWN, 2000, p. 21)

Uma obra expressiva da existência de uma demanda pela integração do jardim moderno à arquitetura moderna é o projeto de Le Corbusier para a casa do arquiteto paisagista Jean Canneel-Clae, em 1931. Cannel-Clae solicitou que a relação entre a casa e o jardim fosse valorizada. No entanto, o comprometimento do espaço do jardim pela garagem e a piscina - ainda que ambientadas em meio a uma vegetação arbórea como é comum nos croquis de Corbusier desse período - foi considerado contrário às suas exigências. Somando-se a isso o custo muito superior ao previsto para a obra, acabou-se decidindo pela contratação de um novo projeto, depois construído, encarregado a De Koninck no mesmo ano. O traçado final do jardim revela alguns padrões que se encontram em outros jardins de lotes alongados do período.

Arquitetos como Eric Mendelsohn e Frank Lloyd Wrightn apresentam posturas bem distintas de Le Corbusier em relação ao tratamento paisagístico de seus projetos. Um dos aspectos de interesse em suas obras é a possibilidade de uma posição dominante da construção no terreno sem prescindir do aproveitamento paisagístico da topografia e de diferentes ambientes externos - jardins, bosques, terraços - aliados à arquitetura.

Outra obra significativa para uma revisão da idéia de que o paisagismo das primeiras décadas do século XX esteve restrito a uma posição subordinada em relação à arquitetura é dada pelo arquiteto sueco Erik Gunnar Asplund. A evolução das propostas apresentadas inicialmente em 1915 por Asplund e Sigurd Lewerentz para o concurso do Cemitério do Bosque, ao sul de Estocolmo ${ }^{\circ}$, permite ver mudanças na concepção do paisagismo que parece mais tarde ter se manifestado também em outros de seus projetos. Já na primeira proposta para o Cemitério, o bosque nórdico existente era o motivo dominante da obra. A implantação se vinculava então à tradição romântica do jardim inglês. Depois de mudanças na situação da capela maior no projeto final, de 1935-40, a ênfase romântica do projeto inicial desapareceu. Em várias pranchas de projetos de arquitetura realizados por Asplund, como, por exemplo, da Escola Secundária Karlshamn, 1912-18; da Biblioteca de Estocolmo 1921; do Crematório do Bosque em Estocolmo de 1935-40, está presente o projeto do paisagismo, mostrando um pensamento efetivamente integrado da solução espacial. 


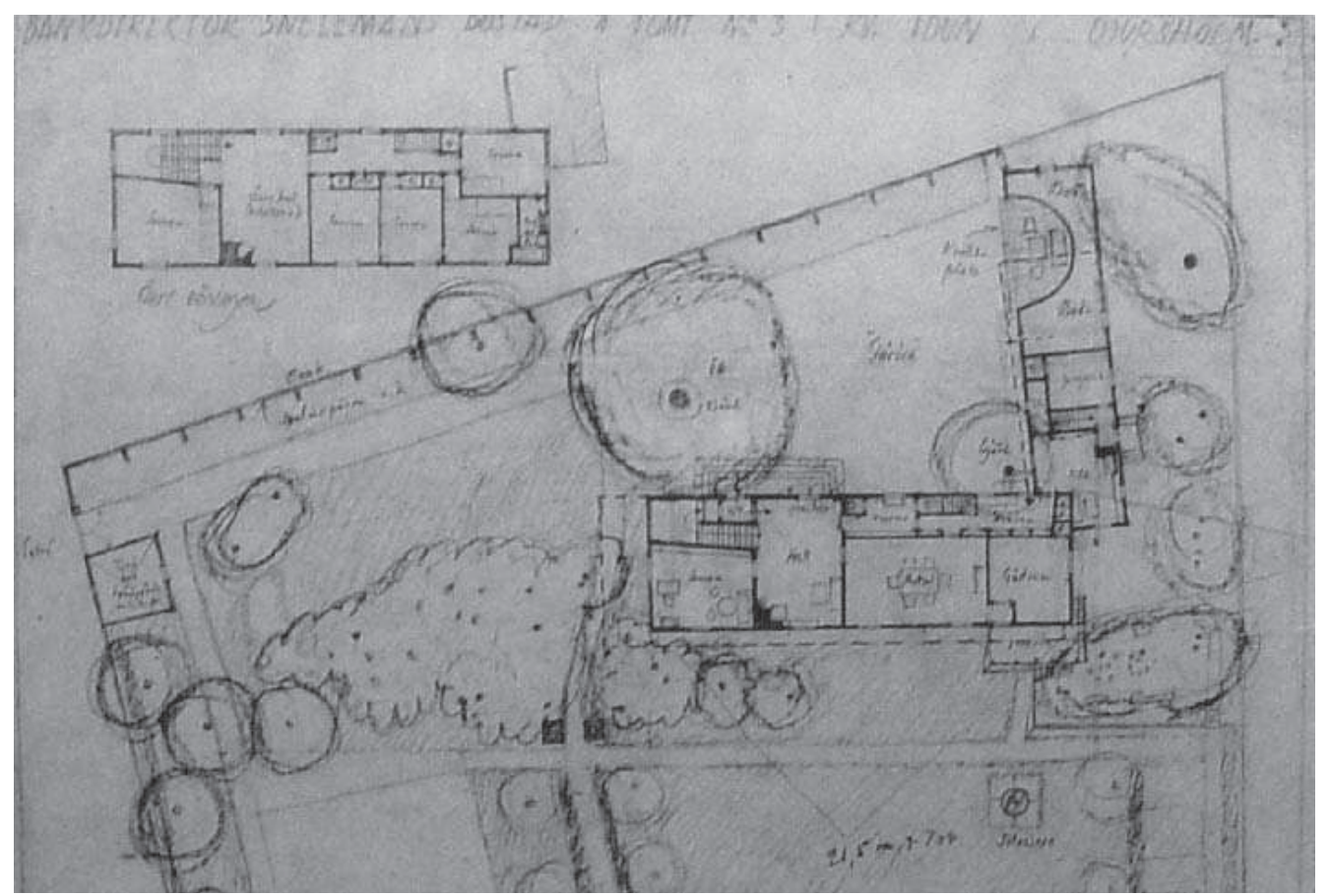

Figura 7: Gunnar Asplund, Villa Snellman (CALDENBY; HULTIN, 1988, p. 62)

\section{Considerações finais}

Pode-se salientar que a aproximação com as vanguardas nas artes plásticas contribuiu para introduzir uma noção de modernidade em jardins da década de 1920 na Europa. Em relação à tendência modernizante derivada das experiências do nascente movimento moderno de arquitetura, pode-se notar que, naquele período, o emprego da vegetação de crescimento livre convive com projetos apresentando vínculos com uma forte experimentação de caráter geométrico e com tradições recentes.

As experiências de paisagistas alemães e franceses sob influência das vanguardas revelam um desejo de superar o jardim naturalista, estabelecendo paralelos formais com o cubismo, futurismo, neoplasticismo e demonstrando forte caráter escultórico. A experimentação em torno a uma estética anti-naturalista será retomada depois em paisagistas como Waldemar Cordeiro e, bem mais recente, Bernard Tschumi, sob outras motivações conceituais e estéticas. Na fase imediatamente seguinte, sobretudo nas Américas, prevaleceu um paisagismo moderno funcionalista (sob forte influência dos mestres do movimento da arquitetura moderna) e com atenção ao ambiente nativo.

Uma nova geração de arquitetos paisagistas estadunidenses como J. Rose, G. Eckbo, L. Halprin, pôde-se formar a partir do contato com as idéias de arquitetos ligados ao movimento moderno (é clara a contribuição de arquitetos e paisagistas modernistas europeus radicados nos EUA, como Gropius e Tunnardp). Pode-se ainda lembrar de Richard Neutra, que emigrou para os EUA em 1923, tendo trabalhado em escritório de paisagismo em Zurich e com Mendelsohn em Berlim, com Wright em Taliesin e, como Rudolph Schindler (com quem trabalhou), desenhou jardins residenciais na Califóniaq. No Brasil, não se pode deixar de repensar a arquitetura "purista" de Gregori Warchavchick com os jardins de sua esposa Minar, atualizado no contexto desse quadro europeu, bem como nos trabalhos iniciais de Burle Marx e de Atílio Correia Limas que na década de 30 apontavam para a constituição de um paisagismo tropical no âmbito de uma reinterpretação característica do modernismo brasileiro das relações entre vanguardas e natureza ${ }^{\dagger}$. A crescente maturidade e originalidade propositiva dos paisagistas nas Américas certamente também poderá ganhar novas interpretações a partir da retomada do contexto europeu das primeiras décadas do século XX. 


\section{Notas}

(1) A historiografia da arquitetura, ainda que muitas vezes reconhecendo a importância da integração das artes para a concepção de um espaço moderno, tende a ignorar o projeto do espaço externo.

(2) Ou a arquitetura da paisagem (landscape architecture), como passa a ser designado a partir de sua estruturação como campo profissional nos EUA. Entre outros termos correntes na Europa nesse período, era freqüente garden architecture.

(3) Na verdade, o paisagismo estadunidense moderno apresentado é o californiano, região na qual aquele autor trabalha.

(4) Mas também se sabe que o paisagismo manteve importante papel nos trabalhos de reconstrução da Europa no primeiro e no segundo pós-guerra (TREIB, 2002), embora vinculado a um desenho de teor nacionalista e tradicionalista.

(5) No caso desse país, possíveis explicações para essa lacuna podem estar ligadas aos aspectos tradicionalistas da cultura arquitetônica estadunidense entre a Exposição Internacional de Chicago (1893) e a política do New Deal (1933-37) - aspectos negligenciados por uma historiografia voltada para a afirmação do movimento moderno.

(6) Como o ICOMOS (Conselho Internacional de Monumentos e Sítios, criado em 1964 durante o II Congresso Internacional de Arquitetos em Veneza, UNESCO), que trata de questões gerais do patrimônio histórico, inclusive "paisagens culturais" e o DOCOMOMO (Documents and Conservation of Buildings, Sites and Neighbourghoods of the Modern Moviment, criado em 1988 na Holanda, que tem uma seção de Urbanism + Landscape).

(7) No Brasil, há um conjunto de trabalhos já concluídos sobre esse período que gradualmente vão lançando um entendimento desse projeto e ampliando seus horizontes: Guaraldo 2002, Sandeville Jr. 1993, 1997, 1999, Dourado 2000, Mariano 2005, Medeiros 2004, são pesquisas ligadas a núcleos paulistanos, mas também há outros núcleos estruturando-se no Rio de janeiro e em Recife, além de pesquisadores isolados em vários outros locais, onde a maior dificuldade ainda é o intercâmbio e o debate dessa produção.

(8) Referimo-nos a aspectos como o espaço contínuo em que interior e exterior se integram, promovendo a integração e simultaneidade ou fusão de interior e exterior; o controle total desse espaço procurando-se uma integração estrutural e uma síntese artística, para a qual colaboram, por exemplo, a pintura em painéis, a escultura e os jardins; uma visão totalizadora e funcional do espaço, promovendo o conceito de plano e de metodologias objetiváveis para o projeto; uma estética construtivista e purista definindo o partido, com recusa dos elementos decorativos na composição do projeto.

(9) Isso se considerarmos também como vanguardas as tendências depois abandonadas pela Bauhaus e por outros arquitetos e que, nas artes plásticas, entretanto, permaneceram reconhecidas como tais, mas na arquitetura foram deixadas de lado diante da "estética do funcionalismo". Isso é coerente com as limitações envolvidas na aceitação de uma história da arquitetura modernista, em sua ortodoxia, como uma história da arquitetura contemporânea. Também na arquitetura, um conjunto de relações entre as demais tendências artísticas e a arquitetura do período (com rebatimentos nos jardins mencionados neste artigo) permaneceu pouco explorado, e só recentemente vai sendo resgatado (PEHNT 1975 sobre "arquitetura expressionista", MAENZ 1976 sobre o Art Déco, que surgem em um contexto de revisão da historiografia modernista).

(10) Mallet-Stevens, um ativo arquiteto ligado às vanguardas, criou em 1924 a União de Artistas Modernos, projetou inúmeros cenários para filmes na década de 20 e foi um dos criadores do CIAM. Apesar de sua intensa produção, foi obliterado na historiografia moderna.

(11) Mas as possíveis afinidades entre a obra de Mondrian - tão avesso à representação da natureza - e a criação de jardins modernos, embora já em parte identificadas, ainda merecem maior aprofundamento.

(12) Como também para a mudança de rumo na arquitetura e no design da Bauhaus.

(13) Pniower foi proibido de trabalhar como paisagista no período do nacional socialismo alemão, acusado de ser meio judeu e de ter sido membro do Partido Social Democrata de Weimar (WOLSCHKE-BULMAHN 2005, GRÖNING 2002).

(14) A contribuição entre Wright e paisagistas como Jens Jensen (que desenvolveu uma estética naturalista de valorização da vegetação selvagem das pradarias ao redor de Chicago, de enorme importância para a história do paisagismo), mostra a atenção desse arquiteto a esse aspecto, como se pode ver no projetos de Wright para as residências da década de 1900, no Hotel no Japão, em Taliesin West.

(15) segundo WREDE 1988:41-46, AHLBERG 1950.

(16) Autor de uma das obras de referência do paisagismo moderno europeu na década de 30, sua residência St. Ann's Hill, Surrey, arquiteto R. McGrath, 1935, e a residência em Bentley Wood, Sussex, arquiteto S. Chermayeff, 1937. Foi autor do importante livro Gardens in the Modern Landscape (1938) pouco antes de mudar-se para os EUA.

(17) Pamela Burton, Marie Botnick. Private Landscapes. Modernist Gardens in Southern California. Princeton Architectural Press, 2003. Disponível em http://www.booklounge.com/books/landscape-architecture/private-landscapesmodernist-gardens-in-southern-california. 
(18) Sandeville Jr. 1993, 1997 notou uma possível semelhança entre esse trabalho e os jardins na casa da rua Bahia, de Mina Warchavchick, advertindo, entretanto que não há evidências para demonstrá-lo e mesmo que houvesse, seriam parciais, dado o partido diverso, muito mais preso a um naturalismo por parte de Mina. Outros trabalhos seus distanciam-se das referências ligadas ao art déco.

(19) Conforme pesquisa ainda inédita realizada por Hugo Segawa.

(20) Sandeville Jr 1993, 1997, 1999

\section{Bibliografia}

AHLBERG, Hakon. Gunnar asplund architect. In: HOLMDAHL, Gustav; LIND, Sven Ivar; ÖDEEN, Kjell. Gunnar Asplund Architect. 1885-1940. Estocolmo: Tidskriften Byggmästaren, 1950.

BROWN, Jane. El jardín moderno. Barcelona: Gustavo Gilli, 2000.

DOURADO, Guilherme Mazza. Modernidade verde. Jardins de Roberto Burle Marx. 2000. Dissertação (Mestrado) - EESC-USP, São Paulo, 2000.

GRÖNING, Gert. Teutonic myth, ruble, and recovery: Landscape architecture in Germany. In: TREIB, Marc (E.). The architecture of landscape, 1940-1960. Filadelfia/Pensilvania: University of Pennsylvania Press, 2002.

GUARALDO, Eliane. Repertório e identidade. Espaços públicos em São Paulo, 1890-1930. 2002. Tese (Doutoradp) - Faculdade de Arquitetura e Urbanismo, Universidade de São Paulo, São Paulo, 2002.

JELLICOE, Geoffrey and Suzan. The landscape of man. Shaping the environment from history to present day. Revised edition. Londres: Thames and Hudson, 1987.

LAURIE, M. An introduction to landscape architecture. 2. ed. Londres: Pitman Publishing Limited, 1978.

LE DANTEC, Jean-Pierre. Le sauvage et le régulier: Art des jardins et paysagisme en France au XXe siècle. Le Moniteur, 2002.

MAENZ, P. Art Déco: 1920-1940. Barcelona: Gustavo Gilli, 1976.

MARIANO, Cássia. Preservação e paisagismo em São Paulo : Otavio Augusto Teixeira Mendes. São Paulo: Annablume, 2005.

MEDEIROS, Givaldo. Artepaisagem a partir de Waldemar Cordeiro. 2004. Tese (Doutorado) - Faculdade de Arquitetura e Urbanismo, Universidade de São Paulo, São Paulo, 2004.

PEHNT, W. La arquitectura expressionista. Barcelona: Gustavo Gilli, 1975.

ROIG, Joan. Jardines modernos: Arquitectura, arte y paisaje em el siglo XX. Arquitectura Viva, n. 53, p. 17-20, 1997.

SANDEVILLE JR., Euler. A herança da paisagem. 1993. Dissertação (Mestrado) - Faculdade de Arquitetura e Urbanismo, Universidade de São Paulo, São Paulo, 1993.

. Anotações para uma história do paisagismo moderno em São Paulo: Elaboração da linguagem e conceituação de um campo entre arquitetos. Paisagem e Ambiente, n. 10, p. 97-166, 1997.

. As sombras da floresta. Vegetação, paisagem e cultura no Brasil. 1999. Tese (Doutorado) - Faculdade de

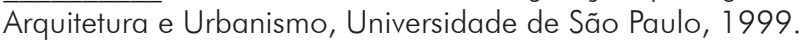

TREIB, Marc. Modern landscape architecture: A critical review. Cambridge: The MIT Press, 1993.

The architecture of llandscape, 1940-1960. Philadelphia/Pennsylvania: University of Pennsylvania Press, 2002.

WAYMARK, Janet. Modern garden design: Innovation since 1900. Londres: Thames \& Hudson, 2003.

WOLSCHKE-BULMAHN, Jachim. Vanguardia y arquitectura de jardín en Alemania. In: BERJMAN, Sonia (Org.). Seminário Internacional Diversas maneras de mirar el paisaje. Buenos Aires: Nobuko, 2005.

WREDE, Stuart. Paisaje y arquitectura: Clássico e vernacular em Asplund. In: CALDENBY, Claes; HULTIN, Olof. Asplund. Barcelona: Gustavo Gili, 1988. 